\title{
El Salvador y los estereotipos de la mujer que prevalecen en su publicidad televisiva
}

Por:

Isabel Alvarado

Licenciada en Mercadeo, Docente e Investigadora del

Departamento de Administración de Empresas

Universidad Centroamericana José Simeón Cañas, UCA.

\section{Jorge Molina}

Máster en Salud Mental y Docente de la

Universidad Centroamericana José Simeón Cañas, UCA.

\section{RESUMEN}

Los estereotipos naturalizan los imaginarios sociales sobre género y sexualidad, por lo tanto, resulta importante avanzar en la investigación de estos temas, con el fin de descubrir diversas aristas que permitan captar, analizar e interpretar los aspectos significativos de las representaciones mediáticas (Muñoz \& Bastidas, 2016). Las diferentes aristas para abordar el tema de estereotipos de género y la violencia que pueden desencadenar son importantes de tomar en cuenta, sobre todo si se habla de que esta reproducción se lleva a cabo en medios masivos como la televisión, y con herramientas como la publicidad.

En El Salvador, la reproducción de estereotipos de género en la publicidad está definida, según el Instituto Salvadoreño para el Desarrollo para la Mujer (ISDEMU), como un tipo de violencia contra las mujeres, específicamente como violencia simbólica (ISDEMU, 2013), Por lo que resulta importante el análisis de esta problemática social desde el punto de vista del mercadeo, específicamente de la publicidad en televisión, que es un medio masivo e importante de transmisión de contenidos publicitarios.

Este estudio tiene como objetivo determinar la existencia de estereotipos de género en la publicidad televisiva de señal abierta salvadoreña, y además identificar los diferentes tipos de estereotipos presentes en dicha publicidad, con el fin de iniciar un camino para, posteriormente, comprender el impacto que estos pueden generar en una sociedad, específicamente, en una tan violenta como la salvadoreña. Así mismo, propone un abordaje interdisciplinario, desde el estudio de las representaciones sociales.

Palabras clave: publicidad, género, estereotipos de la mujer.

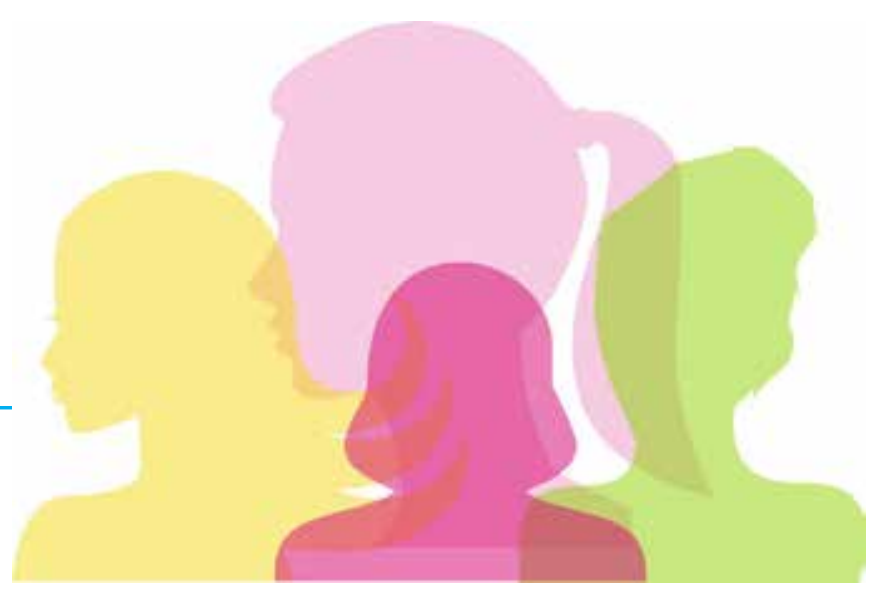

\section{Estereotipos de género}

El término "estereotipo" fue acuñado por primera vez por el periodista Lippman, en el año 1922, para hacer referencia a imágenes culturales que están relacionadas con las facultades cognitivas del individuo y su percepción del mundo que le rodea (Aparici, 2010). Es decir, que los estereotipos reflejan imágenes que no necesariamente son ciertas, pero que pueden serlo para una parte del mundo que se está mostrando, aunque no puede tomarse como un elemento general de la realidad.

Concretamente, un estereotipo es una característica asociada a una categoría cognitiva que es usada por los perceptores para procesar información sobre el grupo o miembros del grupo (Dovidio, 1986). Gaertner definió un estereotipo como un conjunto comprimido de creencias consensuadas sobre las características de un grupo particular (Gaertner, 1973). Además, han sido a menudo conceptualizados como representantes del componente cognitivo del prejuicio (Berges, 2008).

Tomar en cuenta el prejuicio resulta un elemento importante, ya que normalmente, conducen a aceptar una verdad antes de cuestionarse si es del todo cierta o no, y esa verdad está basada en una idea generalmente negativa hacia algo o alguien.

Esas ideas, que forman la base de los estereotipos, son valores diferenciados que se han ido construyendo desde hace décadas y hasta siglos. No son, necesariamente, un reflejo de la realidad social, a menudo están totalmente obsoletas, y no se defenderían racionalmente. Sin embargo, el nivel de arraigo e interiorización que se tiene de estas es enorme, y la sociedad se mueve u organiza tratando de cumplirlas (OVSG-Puebla-UIAP, 2010). 
El hecho de que una sociedad sea capaz de actuar conforme al cumplimiento de los estereotipos resulta una afirmación contundente, ya que existirán diferentes esferas de la sociedad que los reproducirán, incluso sin darse cuenta; lo harán simplemente por el hecho de seguir con la tradición o con la idea que han asimilado como correcta, sin notar que, probablemente, están reproduciendo una burda deformación de la realidad que oculta en su simpleza la complejidad de las realidades sociales (Martín-Baró, La Familia Puerto y Cárcel para la mujer Salvadoreña., 1990). Estas serán siempre complejas, ya que están compuestas por múltiples elementos que no pueden analizarse de forma aislada. Así, se debe considerar la influencia que tienen los estereotipos en todas esas variables que forman parte de la realidad, específicamente de la salvadoreña.

Según ISDEMU, los estereotipos también hacen referencia a una idea fija y repetida sobre lo que creemos propio de todas las mujeres y sobre lo que creemos propio de todos los hombres. "Los estereotipos genéricos uniforman la mente y hacen creer que toda mujer es débil, conformista, incapaz, insegura, pasiva y dependiente" (ISDEMU, 2008). Sobre esta definición es importante destacar que cuando se habla de estereotipos es posible pensar en muchos tipos, que pueden estar basados en la raza, edad, nacionalidad, cultura, género, etc. La definición del ISDEMU hace referencia, específicamente, a los estereotipos de género $y$, además, define que no solamente son concernientes a las mujeres, sino también a los hombres. Sin embargo, resulta imposible negar que la imagen de la mujer sea la que se ha visto más afectada negativa y tradicionalmente a lo largo del tiempo.

\section{Tipología de los estereotipos de la mujer}

El estudio de los estereotipos de la mujer resulta importante debido a que afectan a este grupo en múltiples dimensiones de sus vidas. Por ejemplo, han sido identificados como una de las principales causas por las que las mujeres enfrentan más obstáculos que los varones para alcanzar puestos directivos y de alta responsabilidad (Beaudoux, 2014). Como resultado de la asimilación de la realidad basada en estereotipos, que a su vez se basan en prejuicios, se legitima la asignación de ciertas capacidades, aptitudes o cualidades que corresponden a los hombres 0 a las mujeres. Haciendo referencia específicamente a las mujeres, han existido teóricamente múltiples definiciones de estereotipos que hacen alusión a ellas y a estas cualidades asimiladas como exclusivamente femeninas.

Para comprender de manera uniforme la conceptualización de los estereotipos de la mujer, se utilizaron definiciones de los siguientes autores: Martín Baró (Baró, 1988), Domínguez y Kaufman (Dominguez E, 2008) y García y García (García E, 2004).

El resultado de la codificación y los elementos principales de la conceptualización de cada estereotipo para esta investigación se presenta a continuación: 


\begin{tabular}{|c|c|c|}
\hline Cod. & Estereotipo & Autor \\
\hline 1 & $\begin{array}{l}\text { Coqueta y seductora } \\
\text { Coqueta y seductoraEl primer atributo social es su cuerpo, es decir, su belleza y atractivo sexual. }\end{array}$ & (Martin-Baró, 1988) \\
\hline 2 & $\begin{array}{c}\text { Maternal , hogareña y cuidadora } \\
\begin{array}{c}\text { Mujer integrada a su función familiar, lo que, según el autor, la remite también a su cuerpo, con el hecho } \\
\text { biológico de la maternidad y el cuidado del hogar, del marido y los hijos. }\end{array}\end{array}$ & $\begin{array}{l}\text { (Martín-Baró, 1988), } \\
\text { (Garcia \& Garcia, 2004) }\end{array}$ \\
\hline 3 & $\begin{array}{l}\text { Educadora } \\
\text { Se presenta como fortalecedora de la formación académica de los hijos, presentada en la publicidad } \\
\text { con jóvenes, niños y bebés como símbolo de su crecimiento y evolución como mujer. }\end{array}$ & (Garcia \& García, 2004) \\
\hline 5 & $\begin{array}{l}\text { Independiente y profesional } \\
\text { La mujer que es competente en el ámbito público, capaz de ejercerse profesionalmente, pero además } \\
\text { tiene que compatibilizar su trabajo con la responsabilidad familiar del cuidado de los hijos. }\end{array}$ & (Garcia \& Garcia, 2004) \\
\hline 6 & $\begin{array}{c}\text { Mujer adorno } \\
\text { Se muestra desprovista de inteligencia o personalidad, su fin es adornar el anuncio con posturas } \\
\text { insinuantes. }\end{array}$ & $\begin{array}{l}\text { (Domínguez, Kaufman \& } \\
\text { Marroquín, 2008) }\end{array}$ \\
\hline 7 & $\begin{array}{l}\text { Mujer escaparate } \\
\text { Representa un símbolo del triunfo masculino, es mostrada como un trofeo a través del cual el hombre } \\
\text { conseguirá reconocimiento y admiración. Se muestra como una posesión del hombre para mostrar su } \\
\quad \text { posición social. No tiene identidad propia, no es nada sin su compañero. }\end{array}$ & $\begin{array}{l}\text { (Dominguez, Kaufman \& } \\
\text { Marroquin, 2008) }\end{array}$ \\
\hline 10 & $\begin{array}{c}\text { Mujer niña } \\
\text { Con rasgos infantiles, rodeada de un aura de inocencia y pureza simbolizada por velos y gasas blancas. } \\
\text { No se visualiza la "maligna" intención seductora del personaje. }\end{array}$ & $\begin{array}{l}\text { (Domínguez, Kaufman \& } \\
\text { Marroquín, 2008) }\end{array}$ \\
\hline 11 & $\begin{array}{l}\text { Mujer bella } \\
\text { Relacionada con el cuerpo femenino, se presenta en la publicidad a mujeres jóvenes, guapas, sin } \\
\text { arrugas y con un cuerpo curvilineo "perfecto". }\end{array}$ & (Garcia \& Garcia, 2004) \\
\hline
\end{tabular}

Fuente: Elaboración propia. 


\section{Publicidad, estereotipos y representaciones sociales}

Philip Kotler y Gary Armstrong definen publicidad como cualquier forma pagada de presentación y promoción no personal de ideas, bienes o servicios por un patrocinador identificado. Sus principales objetivos son: informar, persuadir y recordar (Phillip Kotler, 2003). Además, según O'Guinn, Allen y Semenik, la publicidad es un esfuerzo pagado, transmitido por medios masivos de información con el objeto de persuadir (Tomas O'Guinn, 1999). Un elemento común en estas definiciones que es importante considerar es la persuasión que, según la Real Academia Española (RAE), se define como "inducir, mover, obligar a alguien con razones a creer o hacer algo" (Real Academia Española, 2018).

Esto significa que los anuncios publicitarios tienen el poder de hacer creer o ejecutar algo a las personas que estén expuestas a sus contenidos. Cuando ese "algo" es una idea positiva o un elemento digno de imitar, los medios de comunicación son una herramienta muy útil y eficaz, y pueden contribuir a cambiar la mentalidad para mejorar algún aspecto de la sociedad. Sin embargo, cuando esa idea es negativa o es un estereotipo, este modela la percepción de género y la determina.

Los medios manejan a los géneros hasta el punto de hablar de una profecía autocumplida, convirtiendo en realidad las creencias mantenidas, que mediante la representación estereotipada de género construyen y refuerzan las desigualdades entre hombres y mujeres (Aparici, 2010). La problemática principal no radica en las desigualdades de los sexos, sino en que la promoción de esas desigualdades puede generar discriminación, maltrato, falta de oportunidades, cultura machista, entre otros.

Deestemodo, también seabordan las representaciones sociales, las cuales, desde las ciencias sociales, son una aproximación para comprender actos cognitivos por medio de los cuales se produce y reproduce un signo; y este, a su vez, interactúa con la sociedad en un momento de la historia. Asimismo, se entienden como la concepción de imágenes que condensan un conjunto de significados $y$, a su vez, se articulan a los sistemas de referencia que facilitan la interpretación de los sucesos, emergiendo categorías que permiten clasificar circunstancias, fenómenos e individuos (Moscovici, 1984) (Jodelet, 1991).
Comprender a los medios de comunicación desde las representaciones sociales es importante, debido a que estas también están orientadas a la comunicación, la comprensión y el dominio del entorno social, ideal y material. Los estereotipos forman parte de elementos que intervienen en la elaboración de las representaciones sociales, en algunas ocasiones, participando en la interacción de conceptos nuevos en la red de conocimientos previos; facilitando, por un lado, la familiarización con aquello que en un inicio se considera como extraño o novedoso. Y por otro lado, están los modelos interpretativos que orientan las acciones de los individuos, participando también en la difusión de conocimiento, y el fortalecimiento de la identidad (Di Giacomo \& Paez, 1897) (Jodelet, 1991).

En este caso, se considerarán tres tipos de representaciones sociales; las representaciones hegemónicas, que tienen un carácter predominante y coercitivo, y son compartidas de forma amplia por los miembros de un grupo; las representaciones emancipadas, que son compartidas por subgrupos, y poseen cierto nivel de autonomía; y las representaciones polémicas, que emergen de las interacciones conflictivas y polarizadas entre distintos grupos de la sociedad (Moscovici, 1984).

Para el mismo autor, en el campo de las representaciones sociales, también se presentan dos universos de conocimiento diferenciado: el reificado y el consensual. El estudio del universo consensual será de importancia, debido a que este acerca el conocimiento de los eventos sociales y las personas, en una estructura comprensiva, de forma sistemática y siguiendo una jerarquía. Los sistemas de pensamiento en este universo se fundamentan en la autoridad de sus razonamientos y experiencias, siendo ambos los criterios que consolidan en los individuos, de forma oficial, la realidad.

A pesar que este universo es incluyente, muchas veces es diseñado por el universo reificado, excluyente para personas que han adquirido un conocimiento específico. Tal es el caso de los comunicadores, los mercadólogos y los publicistas, quienes destinan gran parte de sus esfuerzos a profundizar en los universos consensuados $y$, en algunas ocasiones, a retomar elementos para que su mensaje, lejos de transformar la realidad, se enfoque en reforzarla (Moscovici, 1984). 
Por consiguiente, la publicidad, más allá de cumplir su finalidad comercial y de mercado, cumple también un fin cultural. Como se ha mostrado a través de los distintos perfiles de mujer que refleja la publicidad, se está alimentando una serie de estereotipos sociales que, aun tratando de evocar elegancia, distinción o elitismo, continúa ensalzando valores asociados a una mujer entendida como un objeto perfecto que persigue belleza y juventud como valores esenciales (Soloaga, 2007).

La finalidad extendida de la publicidad concuerda con que esta estimula, a través de determinados estereotipos, "cómo" o "qué" debe hacer una mujer para ser comúnmente aceptada por la sociedad. Por ello, resulta preocupante que en la actualidad las imágenes que se difunden de la mujer a través de los medios suelan ser negativas y cargadas de estereotipos (Vidales, 2017).

No solamente ese hecho es preocupante, sino que, además, si la imagen de la mujer está definida por estereotipos negativos, muy probablemente la del hombre estará definida por lo contrario. Es decir, es común ver en un anuncio publicitario la imagen de una mujer sensible y de un hombre fuerte, o de una mujer que es ama de casa y de un hombre profesional, e incluso de una mujer inferior y de un hombre que es capaz de hacer todo. Y lo preocupante de esta situación es que estos estereotipos podrían generar discriminación para las mujeres.

Por tanto, se puede afirmar que los medios de comunicación de masas, a través de la publicidad, trabajan simbólicamente con modelos que reproducen y ejercen, de manera sutil, diversos tipos de discriminación, entre los cuales se encuentra la sexista, a partir de elementos culturales y sociales aceptados y, en apariencia, "neutrales" (Astorino, 2016). Cuando esta discriminación sutil se reproduce en la sociedad, puede generar la naturalización de los estereotipos, la discriminación y la violencia de género.

\section{De los estereotipos a la violencia: El Salvador}

La comunicación, históricamente, ha significado el principal vehículo para la transmisión de información en general. Los medios de comunicación masiva o mass media, como se les conoce en la actualidad, han cumplido una importante función en la formación de identidades sociales y de conservación de momentos históricos; más allá de eso, los medios de comunicación, en especial la televisión, han servido para moldear los hábitos de consumo de las personas que a diario utilizan dichos medios, a pesar de ser un servicio regido y moderado bajo ciertas leyes, estatutos y regulaciones. La televisión se ha convertido en el medio más utilizado para la publicación y expansión de productos empresariales, lo anterior data desde finales del siglo XX y lo que ha transcurrido del siglo XXI (SIGET, 2016).

Pero para comprender la comunicación es importante que esta sea abordada desde una visión sistémica, la cual implica también profundizar en la metacomunicación -metamensaje-, el cual aporta un sentido de acuerdo con el contexto, a lo que se pretende comunicar, pero siendo el contexto lo fundamental, debido a que este facilita la codificación adecuada del mensaje. La comunicación es un sistema abierto de interacciones, donde predominan los medios de difusión como eje central en la reflexión, acerca de los vínculos humanos, y la capacidad para comunicarse no solo consigo mismos, sino también con los otros, considerando el entorno simbólico y contextual en que se desarrollan.

La comunicación no es el simple acto de transmitir un mensaje a través de medios, sino más bien, es un acercamiento a las relaciones sociales, compuestas de estereotipos, representaciones sociales, y claro, el imaginario social, pues la comunicación es la base de la interacción social, ya que es un sistema emergente en el proceso de civilización (Bateson y otros, 1981).

La televisión es un medio importante de comunicación. Debido a que es masivo, puede transmitir un mensaje simultáneamente a un número incontable de televidentes. Con esto se afirma la importancia de estudiar los contenidos que son transmitidos a través de este medio, específicamente para este estudio, los anuncios publicitarios televisivos.

Como ya se ha mencionado antes, la transmisión de los estereotipos también sustenta la discriminación, marginación y violencia contra las mujeres, ya que estos son una consecuencia directa de la asimilación hecha durante siglos de estas ideas prejuiciadas de las mujeres. 
Según el artículo 9 de la Ley Especial Integral para un Vida Libre de Violencia para las Mujeres (LEIV) de EI Salvador, sedefinela reproducción deestos estereotipos como "violencia simbólica". Este concepto puede ser comprendido a la luz de la teoría del sociólogo francés Pierre Bourdieu (Bourdieu, 2001), quien delimitaba las interrelaciones de estructuras sociales de desigualdad y percepción, por tanto, la forma en que percibimos la realidad o mundo social tiene origen en ese mismo mundo, generando así, la coherencia necesaria entre nuestra percepción de la realidad, y el mundo que la produce. Así, la naturalización de las desigualdades es, sutilmente, reproducida a través de los medios, pues la violencia simbólica es también internalización y legitimación de una jerarquía. Muchas veces esta se relaciona a la violencia estructural, la cual se manifiesta como desigualdades y jerarquías sociales expresadas, en este caso, en categorías de género, las cuales se reproducen de forma cotidiana, vinculando ambos tipos de violencia a una tercera, la cotidiana, la cual se describe como expresiones microinteraccionales, normalizadas, en ámbitos que van desde el hogar, hasta lo institucional, produciendo así, un "sentido común" de violencia y humillación (Bourdieu, Galtung, Farmer, Scheper-Hughes, citados en Holmes, 2013).

Violencia simbólica: "Son mensajes, valores, iconos o signos que transmiten y reproducen relaciones de dominación, desigualdad y discriminación en las relaciones sociales que se establecen entre las personas y naturalizan la subordinación de la mujer en la sociedad" (LEIV, 2011).

Según el Manual sobre Lineamientos para la Identificación de Tipos y Modalidades de Violencia contra las Mujeres, son ejemplos de violencia simbólica:

"Propaganda televisiva, radial o escrita de carácter sexista, es decir, que reproduce roles y estereotipos de género: mujeres cocinando, mujeres-madres, mujeres amas de casa, mujeres en dobles jornadas de trabajo (casa y trabajo), mujeres débiles, mujeres sumisas, suegras malvadas, utilización del cuerpo de las mujeres como objeto sexual, mujer consumista, sin derecho a ocio, competencia entre mujeres, etc. Hombre-proveedor, hombre-fuerte, hombre propietario de bienes (casas, carros, televisores, etc.), hombre con derecho a ocio (deportes, descanso, paseo, etc.), hombre intelectual, hombre de negocios, hombre sin responsabilidades familiares, hombre líder, hombrepolítica, hombre que sobresale sobre las mujeres. Además, justifican y normalizan la violencia contra las mujeres" (ISDEMU, 2013).

Como resultado de lo que define la LEIV y el ISDEMU en El Salvador, los estereotipos de género en la publicidad son, en sí mismos, una forma de violencia contra las mujeres. Por tanto, erradicar este tipo de violencia debe ser una prioridad en la sociedad salvadoreña. Primero, se debe identificar la existencia de estos estereotipos y los actores que ejercen este tipo de violencia en El Salvador. Este estudio se centra en esta primera etapa del análisis de los estereotipos de la mujer en la publicidad salvadoreña.

\section{Metodología}

Para determinar la presencia de estereotipos de género en la publicidad de televisión abierta salvadoreña, se desarrolló, por un lado, una investigación de carácter cualitativo, debido a que esta permite analizar, comprender y explorar experiencias individuales y subjetivas. En este tipo de investigación, el núcleo central es la experiencia de las y los participantes (Sampieri, Fernández \& Baptista, 2006).

Se utilizó la observación directa, debido a que esta técnica es una poderosa herramienta de investigación social y técnica científica de recogida de información, pues esta desarrolla una forma de comunicación de carácter no verbal entre observador y fenómeno observado. En esta, el investigador-observador se encuentra alerta de las claves que capta e interpreta lo que ocurre a través de dichas claves, logrando la obtención de un conocimiento más sistemático, profundo y completo de la realidad que observa. La observación tiene un carácter intencional y sistemático. Para realizar el estudio fue necesaria la codificación de los estereotipos basada en la conceptualización presentada en el marco teórico de esta investigación. En este caso, la observación fue de modo sistemática, anotando resultados, describiendo y facilitando el establecimiento de relaciones, interpretando y captando un significado (Ruiz, 1999). 
Por otro lado, y a modo de complemento, se desarrolló un análisis cuantitativo, partiendo de un diseño no experimental, y transversal. Fue no experimental porque no existió ningún tipo de manipulación en las variables; y fue cuantitativo debido a que tomó en consideración los puntajes directos arrojados por los instrumentos de medida que, en este caso, estuvieron orientados a un análisis de contenido, en franjas específicas de medios de comunicación masivos. El estudio fue también de corte transversal debido a que fue desarrollado en un periodo específico de tiempo durante el año 2019 (Rojas, 2003).

Además de la definición de los estereotipos, también se tomó en cuenta que el mercado de televisión abierta comercial en El Salvador está ampliamente liderado por el Grupo TCS, a través de sus canales 2, 4, 6 y 35 , que conjuntamente representaron un $66 \%$ del rating promedio en el 2014 . Por lo que se considera el consorcio más grande e impactante de publicidad televisiva a nivel nacional. En adición, el Grupo Megavisión y Canal 12 de televisión representaron, de acuerdo a estadísticas previas, el $21.4 \%$ para el mismo año, sobre la base del rating de los canales 15 , 19 y 21 (SIGET, 2016).

A partir de la identificación de las cadenas televisivas que tienen más presencia en la televisión con señal abierta en El Salvador se seleccionaron los 4 canales que formaron parte del estudio: 4, 6, 12 y 21 .

El análisis estuvo a cargo de un grupo de cuatro observadores previamente capacitados en la conceptualización y comprensión de cada estereotipo. Se le asignó un canal a cada observador, y todos realizaron el análisis de contenido en la misma franja de tiempo. Además, posteriormente al primer análisis, se contrastaban los contenidos observados con todo el equipo para asegurarse de haber realizado un análisis objetivo de los mismos.

Se analizaron todos los anuncios publicitarios transmitidos en estos cuatro canales, durante la franja familiar del día domingo 17 de diciembre de 2017, en el horario de las $06: 00$ a las 18:00 horas. El total de anuncios transmitidos y analizados fue de 128.

El instrumento aplicado fue la adaptación de una matriz de observación utilizada en la investigación "Uso de la imagen de la mujer en la publicidad salvadoreña en los medios impresos y audiovisuales" (M. Hernández, 2013).

El objetivo principal del estudio era determinar la presencia de estereotipos de género en la publicidad televisiva salvadoreña de señal abierta y, de confirmar su existencia, identificarlos.

\section{Resultados}

En los 128 anuncios analizados, se encontró la presencia de estereotipos en el $64.06 \%$ de estos. La distribución final que se obtuvo del análisis de los anuncios televisivos resultó con pocas variaciones según el canal de transmisión.

Del total de anuncios analizados, la mayoría fue transmitida por el Canal 4 (31\%), el $25.6 \%$ por el Canal 6 , el $24 \%$ por el 12 y el $19.4 \%$ por el 21 . Estos datos representan la totalidad de anuncios transmitidos por estos canales el domingo 17 de diciembre de 2017, en el horario de las 06:00 a las 18:00 horas. La cantidad de anuncios transmitidos por cada canal es bastante parecida. Sin embargo, la diferencia principal radica en las marcas que cada canal publicita durante esta franja. 


\section{Gráfico 1. Frecuencia de aparición de marcas}

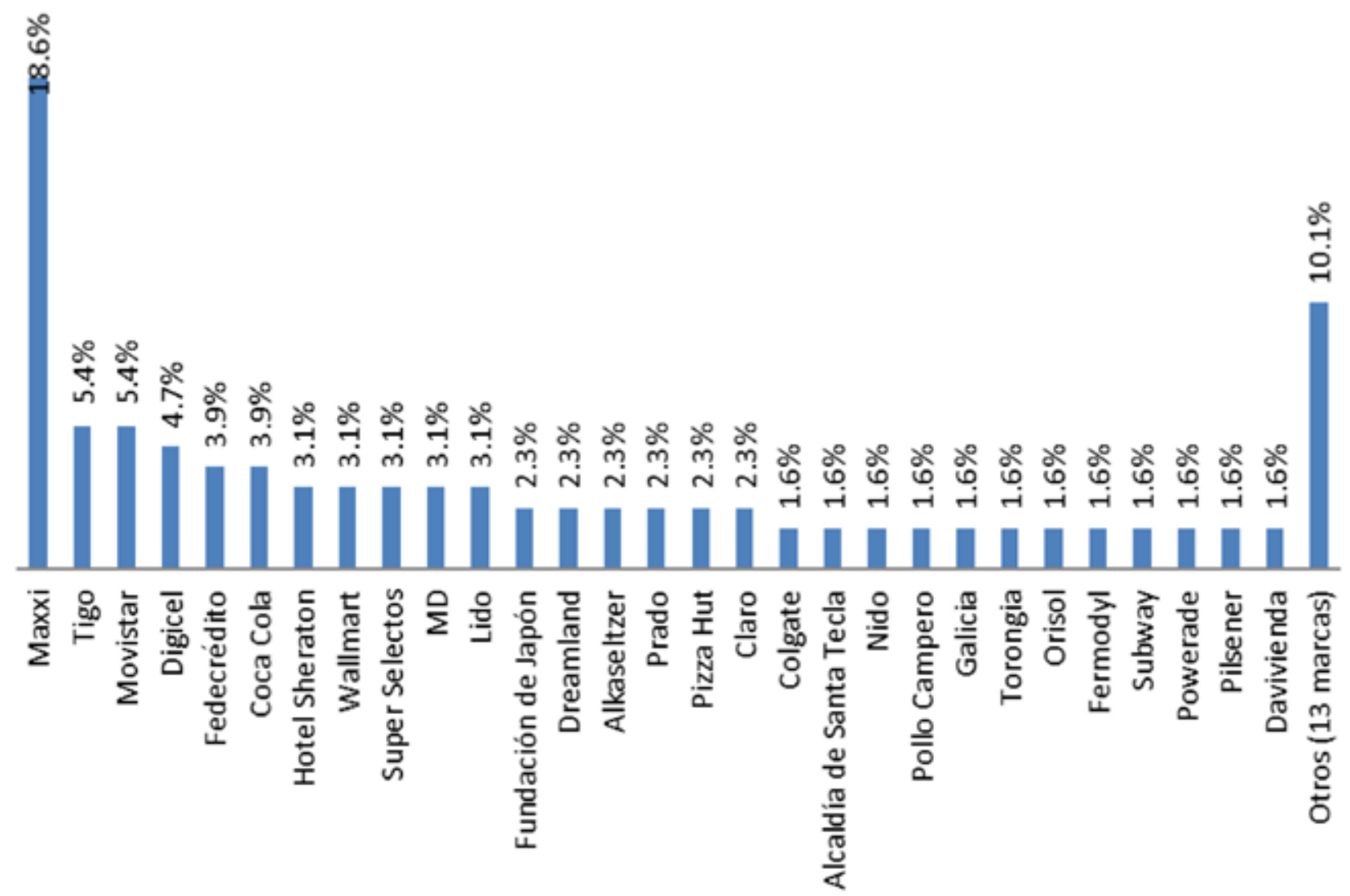

\section{Fuente: Elaboración propia}

En la franja analizada, se observó la presencia de 41 marcas diferentes. La frecuencia de aparición de dichas marcas estuvo dominada por Maxxi con 24 anuncios que representan el $18.6 \%$ del total. Otras marcas que también mostraron una alta frecuencia fueron Tigo, Movistar y Digicel. Algunas de estas marcas son transmitidas solamente por canales determinados. Por ejemplo, los 24 anuncios de la marca Maxxi fueron transmitidos, durante la franja analizada, por el Canal 12. Así, otras marcas como Tigo, Digicel y Coca Cola solamente fueron transmitidas en el Canal 4, y así mismo Wallmart, Super Selectos, MD y Lido en el Canal 6 exclusivamente.

En el Gráfico 1 se muestran las marcas que tuvieron al menos dos apariciones. Las que solamente aparecieron una vez se han agrupado en la categoría "Otros". Como es conocido, cada marca representa a un producto en particular, por lo que las frecuencias de las categorías de los productos corresponden a las marcas analizadas previamente. 


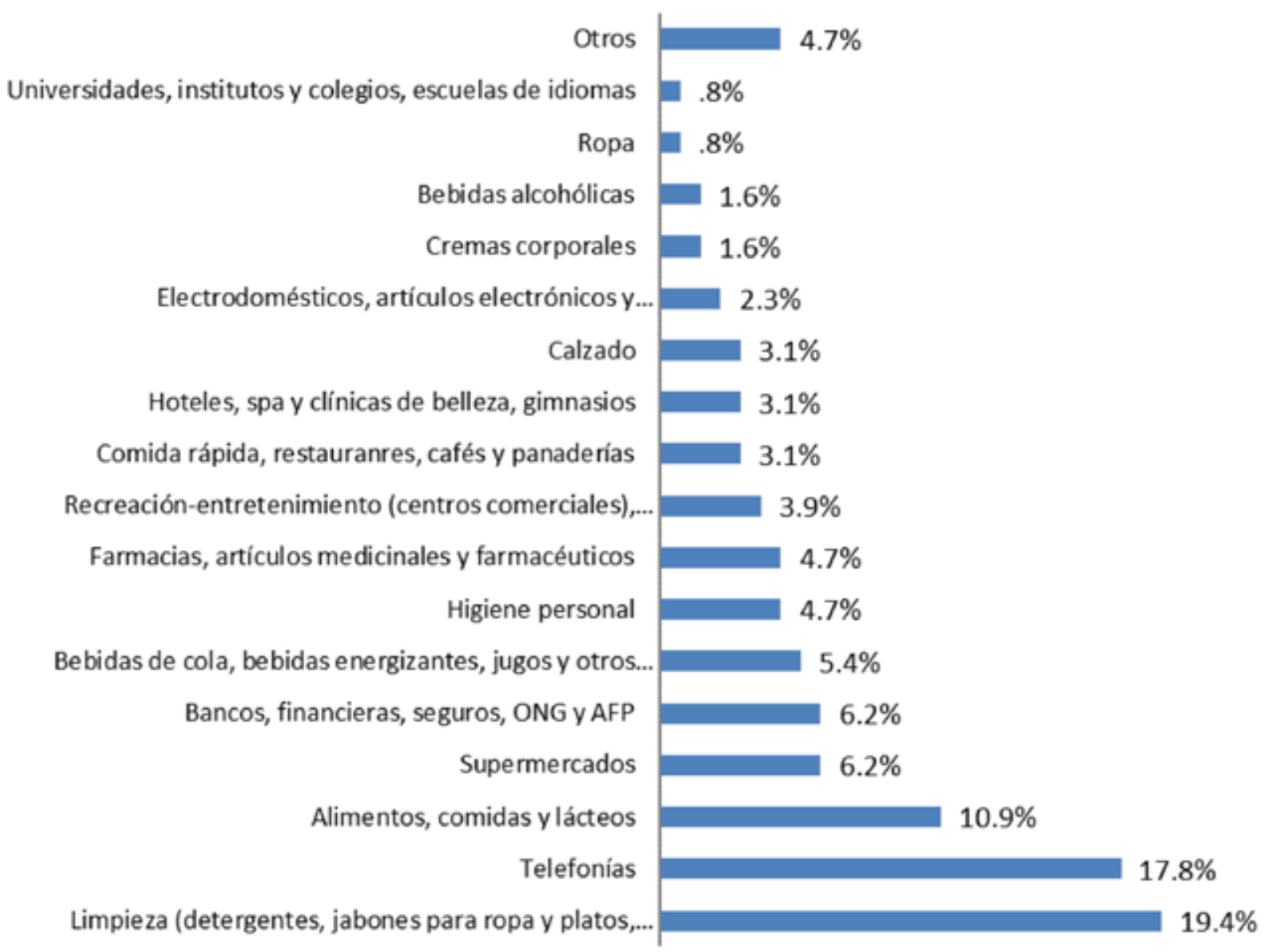

\section{Fuente: Elaboración propia}

Los datos indican que más del $48 \%$ de los productos publicitados se concentra únicamente en tres categorías: artículos de limpieza (19.4\%), telefonías (17.8\%), y alimentos, comidas y lácteos (10.9\%). Es importante considerar las marcas y categorías de productos que tuvieron lugar en el análisis, ya que la presencia de los estereotipos de la mujer estará determinada, en alguna medida, por los tipos de marcas y productos que se publicitaron en la franja de estudio, ya que, lógicamente, será más probable, por ejemplo, que se reproduzca la figura de una mujer como ama de casa en anuncios de limpieza, que el estereotipo de mujer profesional en el mismo.

Este resultado nace de la relación que guardan estas variables generales del estudio. La ilustración 1 refleja la relación directa que guardan entre sí los productos, las marcas y los canales. 
Ilustración 1. Correlación de Pearson en productos, marcas y canales 1

\section{$.412^{* \star} \quad .867^{\star *}$ \\ PRODUCTOS $\rightarrow$ MARCAS $\rightarrow$ CANALES \\ Fuente: elaboración propia \\ 1 ** La correlación es significativa en el nivel 0,01 (2 colas).}

Antes de entrar en el análisis de los estereotipos existentes, es importante destacar que algunos canales van a reproducir más ciertos estereotipos, ya que estos están ligados directamente a los productos, los productos a las marcas, y las marcas a los canales donde son transmitidos los anuncios. La llustración 1 muestra un análisis de correlación de Pearson que confirma esta afirmación, donde la categoría del producto refleja una relación alta con la marca del producto (.412); así mismo la marca con el canal donde fue transmitido, con un resultado de .867 . Por lo tanto, la reproducción de estos estereotipos no estará determinada por el canal, sino por la marca. Por tanto, no podremos afirmar, por ejemplo, que el Canal 21 es el que más transmite cierto estereotipo en sí mismo, sino que esto depende, por ejemplo, directamente de la marca Maxxi, que es la que más se transmitió y únicamente en este canal.
Otro elemento importante que se debe considerar antes de identificar los estereotipos presentes en los anuncios son los protagonistas de los mismos. Para determinarlos, se observó únicamente a la persona que desarrollaba el papel principal durante la transmisión. Se clasificaron en seis categorías diferentes. "Ambos", cuando el hombre y la mujer tenían el mismo protagonismo; "Ninguno" cuando aparecían los dos, pero no se podía determinar un protagonismo más marcado por alguna de las partes; "Femenino" cuando la protagonista era una mujer; "Masculino" cuando era un hombre; y los demás se agruparon en "Niños", independientemente el sexo; y en "No Aplica", cuando en el anuncio no aparecían personas.

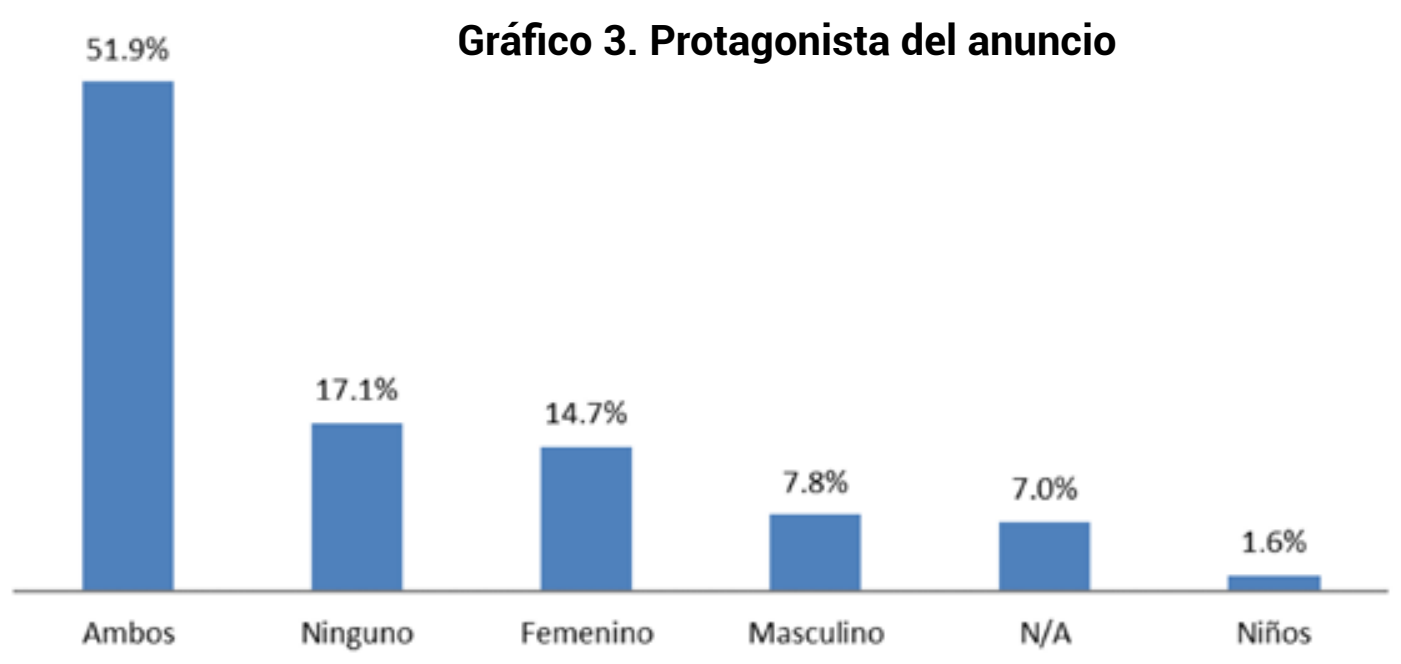

Fuente: Elaboración propia

La mayoría de anuncios utiliza la imagen del hombre y la mujer juntos para transmitir el mensaje publicitario. Las mujeres aparecieron en el $14.7 \%$ de los anuncios analizados y los hombres en el $7.8 \%$. Este resultado evidencia que la utilización de la imagen de la mujer sola para vender se utiliza en una proporción superior, casi duplicando en porcentaje la del hombre. 


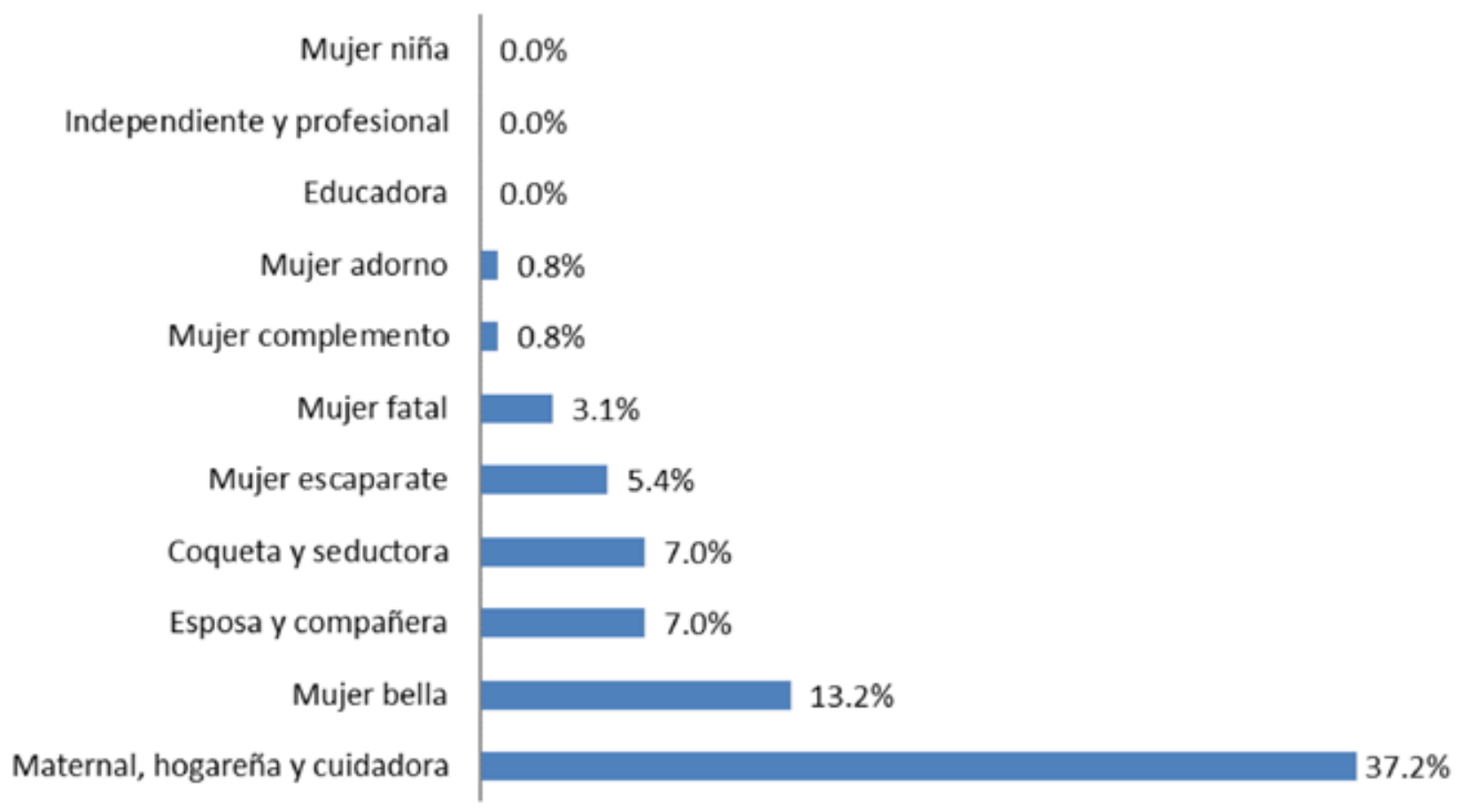

Retomando el panorama general de los anuncios televisivos analizados, donde la mayoría de marcas y productos hacen referencia a categorías de limpieza, telefonía y alimentos, y donde, aparte de la utilización de ambos sexos juntos, la presencia de la mujer supera, por mucho, la del hombre en el protagonismo del anuncio, los estereotipos identificados fueron los siguientes:

\section{Gráfico 4. Estereotipos predominantes}

\section{Fuente: Elaboración propia}

Además de notar claramente en el Gráfico 4 la sobresaliente frecuencia del estereotipo "Maternal, hogareña y cuidadora" y el de "Mujer bella", es importante destacar la ausencia de algunos estereotipos en los anuncios. "Independiente y profesional" y "Educadora" son estereotipos que reproducen aspectos positivos de las mujeres (Anker, 2017), pero que no están presentes en los anuncios televisivos de este análisis. Por el contrario, se destacan la mujer "Maternal, hogareña y cuidadora", la "Mujer bella", la "Esposa y compañera", "Coqueta y seductora", los cuales no denotan las capacidades que podrían hacer llegar a una mujer a desempeñar, por ejemplo, puestos de liderazgo o trabajos no tradicionales para las mujeres, como ingenieras, arquitectas, guardias de seguridad, etc., sino que las ubican en niveles de desarrollo profesional inferiores.

Es importante destacar que existe una diferencia entre los estereotipos que son reproducidos según el protagonista del anuncio. La relación directa del tipo de estereotipo con el protagonista del anuncio $y$, además, también con la marca, se refleja, nuevamente, aplicando el análisis de correlación de Pearson. 
Fuente: elaboración propia

2 ** La correlación es significativa en el nivel 0,01 ( 2 colas).

El valor de la correlación entre la variable "Estereotipo" y la variable "Protagonista" es 0.562 y entre "Estereotipo" y "Marca" es -0.488. En el primer caso existe una relación positiva, y en el segundo, una relación negativa. La correlación se complementa con la probabilidad asociada al estadístico $(P)$, que en este caso es de 0.01 , encontrándose por debajo de 0.05. Por tanto, se concluye que ambos valores de la correlación son significativos, es decir que ciertos estereotipos se reproducen más frecuentemente cuando determinado protagonista está presente en el anuncio o cuando el anuncio corresponde a una marca determinada.

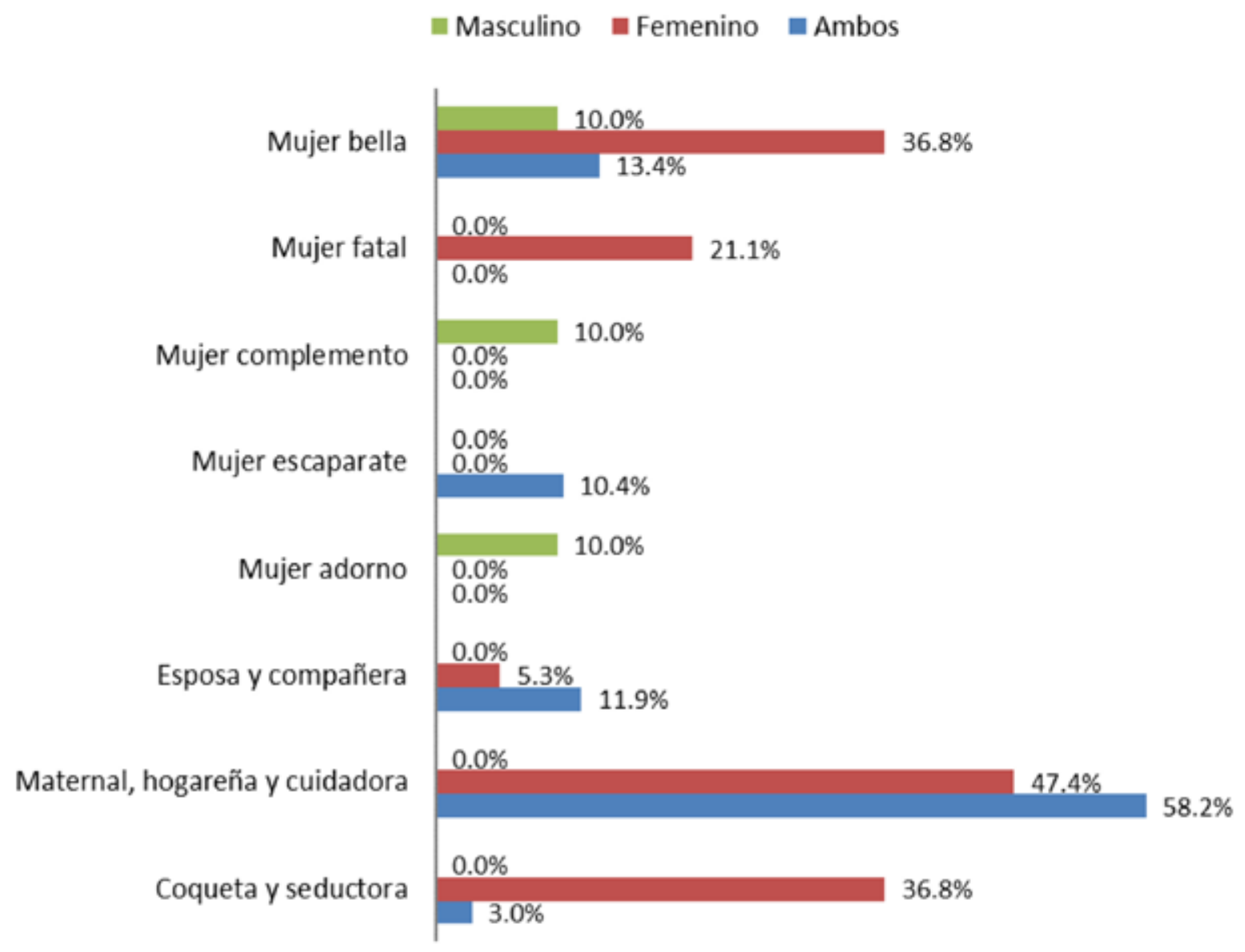

Fuente: Elaboración propia 
El Gráfico 5 muestra un comparativo de los estereotipos que se encuentran presentes cuando el protagonista es un hombre, cuando es una mujer, o cuando son ambos. Es importante mencionar que, del total de estereotipos, el $74.4 \%$ se reprodujo cuando los protagonistas eran "Ambos", el $23.2 \%$ cuando la protagonista era una mujer, y el $2.4 \%$ cuando era un hombre. Es decir que la mayoría de estereotipos se reproducen cuando una mujer está presente, ya sea sola o acompañada por un hombre.

Es evidente que cuando los protagonistas del anuncio son "Ambos" el estereotipo que más se reproduce es el de mujer "Maternal, hogareña y cuidadora". Mientras que cuando la protagonista del anuncio es la mujer, además del estereotipo de "Maternal, hogareña y cuidadora", también entran a escena los de "Mujer bella" y el de "Coqueta y seductora". Es decir, que cuando la mujer aparece sola se destacan atributos diferentes a cuando aparece en compañía de un hombre, donde mayoritaria y significativamente (en un $58.2 \%$ de los casos) se destacan sus cualidades como madre, cuidadora del hogar, etc. Este hecho podría indicar que la presencia de un hombre en el anuncio mengua, de alguna manera, las cualidades de la mujer, destacándolo posiblemente a él en roles masculinos positivos.

Finalmente, se destaca que los estereotipos presentes en la publicidad televisiva salvadoreña guardan una relación directa con el protagonista del anuncio $y$, además, con la marca que se publicita $y$, por consiguiente, con el canal donde se transmitió el anuncio. Así, continuando con el ejemplo de Maxxi, esta marca está directamente relacionada con el estereotipo "Maternal, hogareña y cuidadora", ya que se comprobó que este estuvo presente en cada uno de sus anuncios. Además, al ser un producto de limpieza del hogar, es más vulnerable para reproducir este estereotipo. Y por ser una marca que solamente se publicita en el Canal 21, se le relaciona a este directamente con la reproducción de la imagen de la mujer "Maternal, hogareña y cuidadora". Otros ejemplos relacionados totalmente a este estereotipo son las marcas Lido, Orisol, Torongia, Wallmart y Nido, las cuales, como es notable, hacen alusión a productos de consumo para el hogar.

Por otro lado, marcas como Coca Cola, Pilsener y Pizza Hut aún reproducen el estereotipo de "Mujer bella", es decir que utilizan la imagen de la belleza perfecta para publicitar los productos; normalmente usan mujeres jóvenes, con cuerpos perfectos.

Es importante destacar que los estereotipos también podrían estar relacionados con el grupo objetivo (target) al que las marcas dirigen su publicidad, ya que las mencionadas, primeramente, van dirigidas generalmente a amas de casa, mientras que las segundas, a un target más juvenil y en el que también entra en escena una marca como Pilsener, que se dirige, en gran parte, a hombres.

Un caso muy particular fue el de la marca MD, ya que, de todos los contenidos, es la marca que más estereotipos reproduce en su publicidad. "Mujer bella", "Coqueta y seductora" y "Mujer fatal" son los que estuvieron presentes en todos los anuncios analizados. Es decir, que el primer atributo que destacan en su publicidad es el cuerpo de la mujer y su atractivo sexual, además de mostrarla como una mujer insinuante y misteriosa, a la que los hombres no tienen por qué ver como mujeres inalcanzables.

\section{Conclusiones}

La publicidad y los estereotipos son dos temas que se encuentran íntimamente relacionados, ya que muchas marcas estarán dispuestas a hacer lo que sea por vender su producto, por ganar reconocimiento de marca, por entrar a la mente del consumidor o simplemente para darse a conocer. Ese "lo que sea" puede estar compuesto por muchos elementos atractivos para los clientes, entre ellos el uso inadecuado de la imagen de la mujer en su publicidad, porque, claramente, mostrar una mujer social y culturalmente reconocida como "atractiva" o "bonita" en un anuncio resultó ser un factor más dominante; no importando si esa imagen de la mujer implica la asimilación de una mujer débil, incapaz o inferior, no importa si muestran solamente a mujeres "bellas", cuyo estándar de belleza es inalcanzable y que finalmente puede generar que niñas o mujeres vean afectada su autoestima y desarrollo personal. Tampoco importa si la imagen de la mujer débil provoca un sentimiento de inferioridad en ella, que se ha visto normalizado desde el inicio de los tiempos, o si esta misma imagen va a provocar discriminación hacia las mujeres, e incluso, violencia de género. 
En El Salvador, las marcas están reproduciendo principalmente cuatro estereotipos para vender sus productos en anuncios de televisión nacional: "Maternal, hogareña y cuidadora", "Mujer bella", "Esposa y compañera" y "Coqueta y seductora". A pesar de que los atributos que definen a estos estereotipos podrían asimilarse como sanos o sin ninguna intención dañina, porque son atributos propios de la mujer y además, según la sociedad no hay nada de malo en ser una buena madre, una buena esposa, en ser bella o coqueta. A pesar de esto, la reproducción de estas imágenes puede tener consecuencias negativas en la vida de las mujeres.

Esto responde a una forma de presentar a la mujer desde la imagen machista, plasmada en una serie de estereotipos, en medios de comunicación masiva $y$, por ende, siendo producto de la forma de hacer publicidad en el contexto salvadoreño.

Será importante, en posteriores investigaciones, analizar los procesos de formación y construcción social del publicista en la realidad nacional. Pues en este contexto, aún se mantiene una imagen ideal de la mujer, desde el machismo, el cual tiene a su base, un modelo de masculinidad hegemónica. En palabras de Martín-Baró: "La existencia de una imagen machista de la mujer, imagen supuestamente "ideal", sirve como principio orientador para los procesos de socialización sexual y como raíz de las expectativas sociales respecto al papel de la mujer" (Martín-Baró, La imagen de la mujer en El Salvador, 1980).

Por ejemplo, cuando se educa a las niñas en la sumisión y la dependencia, enseñándoles a servir y obedecer, en la realización de las labores domésticas o en la guía hacia una sola meta, que es el matrimonio, esto limita a las mujeres, sus vidas y su universo.

Desafortunadamente esto se reproduce y se ha reproducido de generación en generación. La sumisión y dependencia se traducen en trabajos subordinados, como trabajadoras domésticas, trabajadoras en la maquila, estar siempre bajo las órdenes de un patrón varón, sea el jefe, el padre, el hermano y hasta el hijo (OVSG-Puebla-UIAP, 2010). Los anuncios televisivos son, en El Salvador, una herramienta importante en la reproducción de estos estereotipos, ya que más del $60 \%$ de los mismos reproduce alguno de los tipos definidos en esta investigación.

Las representaciones sociales encontradas en la construcción estética de objetos representados -en medios-, en este caso de la mujer desde una concepción machista, se sitúan en un imaginario que condensa, a través de los estereotipos antes mencionados, un conjunto de significados, y se articula a un sistema de referencia, desde los modelos de masculinidad tradicional y hegemónica. Esto se hace manteniendo formas de categorizar que, a su vez, sirven para clasificar e interpretar sobre el rol de la mujer en la sociedad formas que no solo limitan, sino que también contribuyen a legitimar relaciones de tipo sistémico-estructural basadas en la desigualdad.

En este caso, las instituciones que generan el contenido y aquellas que lo promueven, propician las relaciones desiguales entre hombres y mujeres. Dichas representaciones pueden ser también comprendidas desde la idea de (Goffman, 2006) sobre el estigma, quien plantea que el estigma surge cuando el grupo al que pertenece un individuo identifica algún elemento que lo hace diferente en niveles físicos, tribales o psicológicos, entendiendo el estigma como una clase especial de relación entre atributo y estereotipo.

Desde esta noción, las mujeres que no siguen dichos estereotipos no se encuentran dentro de lo "normal", y promover una representación social de la mujer desde el machismo ayuda a la persistencia de acciones, discursos y prácticas de naturaleza patriarcal, que impiden cambios a favor de la equidad y la justicia de género, áreas tan necesarias en el rompimiento de las inercias culturales.

Además, es importante notar que el estereotipo de "Mujer independiente y profesional" no estuvo presente en ninguno de los anuncios analizados. Esto es interesante, ya que reafirma cómo el proceso de socialización de género nos ha limitado al dictarnos las actividades, las ideas, creencias y hasta los sueños y deseos diferentes para hombres y mujeres. 
La socialización en nuestra cultura hace que se considere a las mujeres más "aptas" para cierto tipo de tareas, y a los hombres "aptos" para lo opuesto o contrario (OVSG-Puebla-UIAP, 2010). Es decir que ha sido socialmente aceptado que el hombre sea quien tiene la capacidad para trabajar y desarrollarse profesionalmente; en contraste con la mujer, quien debe desarrollarse aún desde el rol de cuidadora en la casa, con los hijos e hijas, e inclusive con personas que requieran un cuidado especial, como el caso de ancianos, por ejemplo.

Basados en esta idea, no se muestra en los anuncios salvadoreños a una mujer profesional, capaz de desarrollarse independientemente y en cualquier profesión. Al contrario, se muestra una mujer tradicional, realizando tareas femeninas exclusivas y sin oportunidad de realizar actividades laborales en trabajos especializados.

Es también significativo notar que cuando ambos personajes, hombre y mujer, aparecen como protagonistas en los anuncios, la reproducción de estos estereotipos aumenta. La aparición del hombre junto con la mujer guarda una relación directa con el estereotipo que se reproduce en el anuncio.

Sería importante estudiar, en contraste, el estereotipo masculino, que se reproduce cuando los protagonistas son ambos, para determinar si la presencia del hombre en el anuncio mengua la de la mujer, en el sentido de mostrar una imagen menos valorada de ella y más estimada del hombre cuando están ambos presentes en el anuncio. Como lo demostró el análisis de correlación, los protagonistas están relacionados directamente con los estereotipos, estos con los productos y las marcas, y estas últimas con los canales.

Partiendo de eso es posible identificar los productos y marcas que son más vulnerables a reproducir estos estereotipos. Lógicamente los relacionados con los productos del hogar son los que representaron estas imágenes en su mayoría.

La reproducción de estos estereotipos genera que se siga viendo a la mujer como alguien apta únicamente para cuidar, ser ama de casa, vender más porque es bonita, o como alguien coqueta que puede obtener ventaja de eso para llegar adonde lo desea. La publicidad, vista desde otro ángulo, podría orientarse a transformar la visión tradicional desde la imagen machista de la mujer, y más bien, promover la imagen de la mujer en puestos de trabajo no tradicionales, haciéndola ver capaz de desempeñar cargos en áreas de dirección, construcción, seguridad, ciencia, entre otros.

El problema no radica en destacar la diferencia entre hombres y mujeres en los anuncios, porque así debe ser, ya que son seres diferentes por naturaleza. El problema es que esas diferencias pueden vincularse y legitimar desigualdades, abonando a la violencia simbólica, estructural y cotidiana; expresándose en el trato, el acceso a oportunidades de crecimiento y desarrollo profesional, su auto valoración, entre otras. Esas desigualdades pueden conllevar incluso a naturalizar la violencia contra las mujeres $\mathrm{y}$, así como se mostró en este estudio, existen marcas que reproducen estereotipos de género que son considerados, según la ley salvadoreña, como violencia simbólica contra las mujeres.

En El Salvador, un país donde la violencia es uno de los principales problemas y que se ubica como uno de los diez países con peor índice de criminalidad en el mundo (Verisk Maplecroft, 2016), es importante analizar más a profundidad los fenómenos que puedan influir en esta problemática. $Y$ desde esta visión, abonar a una transformación no solo en los estereotipos en marcas y en medios de comunicación, sino también en la forma de hacer publicidad. 
Anker, R. (2017). La segregación profesional ente hombres y mujeres. PNUD, Ginebra. Aparici, R. (2010). La construcción de la realidad en los medios de comunicación. España: Universidad Nacional de Educación a Distancia.

Astorino, M. \&. (2016). Estereotipos de género en publicidades de productos orientados al público infantil en Argentina. Ánfora, 17-50.

Baró, M. (1988). La mujer salvadoreña y los medios de comunicación masiva. Revista de Psicología de El Salvador, 253-266. Bateson, G., Scheflen, A., Birdwhistell, R., Hall, E., Jackson, D. W., Sigman, S., \& Goffman, E. (1981). La nueva comunicación. Barcelona: Kairós.

Beaudoux, V. (2014). Influencia de la televisión en la creación de estereotipos de género y en la percepción social del liderazgo femenino. La importancia de la táctica de reencuadre para el cambio social. Ciencia Política, 9(18), 20.

Berges, B. M. (2008). Discriminación, prejuicio, estereotipos: conceptos fundamentales, historia de su estudio y el sexismo como nueva forma de prejuicio. Revista Electónica Universidad de Jaén, 16.

Bourdieu, P. (2001). Masculine Domination. Stanford: University Press.

Di Giacomo, J., \& Paez, D. (1897). Teoría y métodos de análisis de las representaciones sociales.

Pensamiento, Individuo y Sociedad: Cognición Social y Representación Social. Madrid: Fundamentos.

Dominguez E, K. J. (2008). La discriminación del género femenino en las notas informativas de El Diario de Hoy. San Salvador.

Dovidio, E. T. (1986). J Exp Soc Psychol, 22-37.

Gaertner. (1973). Pers Soc Psychol, 335-341.

García E, G. I. (2004). Los estereotipos de la mujer en la publicidad actual. Cuestiones publicitarias, 1(9), 43-64.

Goffman, E. (2006). Estigma. La identidad deteriorada. Buenos Aires: Amorrortu Editores. ISDEMU. (Noviembre de 2008). Instituto Salvadoreño para el Desarrollo de la Mujer.

Obtenido de Instituto Salvadoreño para el Desarrollo de la Mujer: isdemu.gob.sv

ISDEMU. (2013). Manual sobre lineamientos para la identificación de tipos y modalidades de violencia contra las mujeres. 48. Jodelet, D. (1991). Madness and Social Representations. Living with the Mad in One French Community. Harvester Wheatsheaf. LEIV. (2011). Ley Especial Integral para una Vida Libre de Violencia para las Mujeres. El Salvador

M. Hernández, O. A. (2013). Uso de la imagen de la mujer en la publicidad salvadoreña en los medios impresos y audiovisuales. (U. C. Cañas, Ed.) San Salvador.

Martín-Baró, I. (1980). La imagen de la mujer en El Salvador. Revista de Estudios Centroamericanos, 35(380). Martín-Baró, I. (1990). La Familia Puerto y Cárcel para la mujer Salvadoreña. Revista de Psicología de el Salvador, Vol. (IX), N³7, pp.265-277.

Moscovici, S. (1984). The Phenomenon of Social Representations. Cambridge, University Press.

Muñoz, F., \& Bastidas, C. (2016). Las comedias de situación (sitcoms) producidas por la televisión ecuatoriana y los estereotipos de género. Chasqui.

OVSG-Puebla-UIAP. (2010). Cuaderno 1: Género y violencia. Cuaderno 1: Género y violencia, 23. Phillip Kotler, G. A. (2003). Fundamentos de Marketing (Sexta ed.). Prentice Hall. Real Academia Española. (2018). Diccionario de la lengua española.

Rojas, R. (2003). Guía para realizar investigaciones sociales. México D.F.: Plaza y Valdés.

Ruiz, J. (1999). Metodología de la investigación cualitativa. Bilbao: Universidad de Deusto.

Sampieri, R., Fernández, C., \& Baptista, P. (2006). Metodología de la investigación. México: McGraw-Hill.

SIGET. (2016). El Salvador adopta el estándar ISDB-TB para la televisión digital. El Salvador.

Soloaga, P. D. (2007). Valores y estereotipos femeninos creados en la publicidad gráfica de las marcas de moda de lujo en España. Análisi, 27-45.

Tomas O’Guinn, A. C. (1999). Publicidad. International Thomson Editores. Verisk Maplecroft. (2016). Índice de criminalidad.

Vidales, R. (2017). Estereotipación de la mujer en la publicidad política. Análisis de los estereotipos de género presentes en los spots electorales de la campaña 2015 en Nuevo León. Comunicación y Sociedad, 29, 69-91. 